\title{
Numerical Modeling of Dust Lifting from a Complex-Geometry Industrial Stockpile
}

\author{
Lovrenc Novak ${ }^{1}$ - Benjamin Bizjan1,2,* - Jure Pražnikar ${ }^{3}$ - Boris Horvat2,3 - Alen Orbanić2,3 - Brane Širok ${ }^{1}$ \\ 1 University of Ljubljana, Faculty of Mechanical Engineering, Slovenia \\ 2 Abelium Research and Development, Slovenia \\ 3 University of Primorska, Institute Andrej Marušič, Slovenia
}

This paper investigates the dust lifting phenomenon at the coal and iron ore stockpile at the Port of Koper, Slovenia. Dust lifting presents a serious environment and health hazard, thus the main objective of our study was to propose efficient measures for wind erosion reduction. A numerical model of the stockpile was created using the computational fluid dynamics (CFD) software. Wind velocity fields above the piles were calculated for the current stockpile layout and for several modified cases with rearranged piles and added porous barriers. Results from numerical modelling were used in the USEPA model to determine dust emission factors. Comparison of selected cases shows a positive, although limited effect of porous fences and barriers on reduction of local velocities and consequently, dust erosion rate. On the other hand, pile rearrangement has little effect and may not be practical for implementation. Realistic stockpile geometry with adjacent structures has shown to cause wind velocity distributions, which are not consistent with the most studied cases of regular pile shapes and layouts. The angle of incoming wind is a key factor influencing effectiveness of both solid and porous windbarriers. The proposed placement of porous barriers between the piles has shown to be effective in reducing wind exposure and dust emission. To maintain the dust emissions at an acceptably low level, other measures such as spraying with water and crust-forming liquids may still be necessary at higher wind velocities.

Keywords: computational fluid dynamics, fugitive emissions, dust lifting, open storage pile, emission factor, wind velocity

Highlights

- $\quad$ Wind-driven dust lifting from port stockpile was studied.

- $\quad$ Wind speed across piles was calculated numerically using CFD software.

- Solid fences provide a very limited wind protection.

- Porous fences significantly reduce total emission rate.

- $\quad$ Properly placed transverse barriers reduce wind velocity and emissions.

\section{O INTRODUCTION}

Wind-driven erosion of fine particles from granular materials stored in open stockpiles, also known as dust lifting, is one of the main environmental and safety issues of modern-day seaport operations. Most problematic in this respect are loose dry materials such as coal and iron ore due to the high fugitive emission potential during handling and storage. Large open stockpiles, such as those typically encountered in cargo ports, are especially problematic due to their exposure to wind. Different wind erosion mechanisms can be identified depending on the ratio of wind induced aerodynamic forces (lift and drag) and gravity force, such as creep, saltation and suspension [1]. The wind-induced fugitive dust emissions result in material loss from the stockpile and at the same time increase particulate matter concentrations, with significant health hazards when particles are transported to urban areas. Particulate matter emissions have become a global health issue as negative effects are observed at all levels of exposure [2], therefore particulate emissions must be reduced as much as possible.
Over the last decade, computational fluid dynamics (CFD) with experimental validation has been used extensively for analysis of flow structures over different stockpile configurations. Badr and Harion [3] and [4] used 3D numerical simulations and validated them for wind tunnel measurements. Toraño et al. [5] found that the semicircular pile shape lowered dust emissions and study made by Turpin and Harion [6] showed that the flat-topped pile configuration is the most favorable shape to lower dust emissions. In very complex sites such as ports and power plants, where " $24 / 7$ " activity is present, it is not possible to perform on-site experimental studies due to instrumentation and logistical limitations. In such cases, CFD simulations alone can be used as an alternative tool for engineers to improve the understanding of flow processes at fine spatial resolution and to evaluate emissions at particular industrial sites [7].

To accurately evaluate occurrence of windinduced erosion in ports and other industrial sites, stockpiles should not be considered as individual elements. An aggregate storage yard is composed of many stockpiles in addition to obstacles such as 
buildings and cranes, which can affect local wind distribution [8]. Stockpile arrangement at storage yards was found to significantly affect the dust lifting. The simulation performed by Diego et al. [9] showed that the front pile creates a "shadow" of wind over the back pile, thus emission of adjacent piles are not equal. Another step forward was made by Cong et al. [10] who studied 16 stockpiles arranged in 4 rows and 4 columns. Their analysis showed that total dust emission is increased when the distance to the adjacent piles is raised and vice versa. Therefore, in order to evaluate emissions from a particular stockpile, adjacent piles should also be considered. Calculations by Furieri et al. [11] showed that not only piles, but areas surrounding the piles could contribute significantly to the total emission of dust particles. Furthermore, the simulations made by Turpin and Harion [8] revealed a significant effect of adjacent buildings. In their simulation, three very long stockpiles were included in the calculation domain. While this may be a common situation in a power plant storage yard, the situation is very different at port terminals where coal is transported from different destinations and is then delivered to various customers. Coal at terminals cannot be "mixed up" to form a large single coal pile, therefore it is common that coal is warehoused in a large number of piles. The size, location and arrangement of piles is set up in a way to allow fast and efficient coal handling for the port authorities, suppliers and customers. Additionally, rearrangement or resizing of stockpiles to reduce fugitive emissions is often restricted by crane capabilities and placement of adjacent buildings, meaning that large-scale modifications may not be practical and economically justified. Taking all these issues in consideration, modeling of an actual configuration presents a challenge and an opportunity to improve the understanding of fugitive emissions.

In this study, we have used measured wind speeds and directions to simulate realistic scenarios in the cargo port. The height, size, arrangement and shape of piles were set to represent the most commonly used distribution of coal at the fully occupied port terminal. Moreover, surrounding buildings, solid fence and cranes were also included to achieve a more realistic model. Simulations of air flow in the model were performed by employing state-of-the-art CFD simulations. Additionally, simulated data were used to estimate emission rates by using the United States Environmental Protection Agency (EPA) emission formulation.

\section{METHODS}

\subsection{Location and meteorological conditions}

The Port of Koper is located in northern Adriatic Sea (Fig. 1a) and it covers about $5 \mathrm{~km}^{2}$. It is a multipurpose port and the basic activities in the Port of Koper are handling and warehousing of various cargos conducted at three terminals. At one particular terminal, named the European energy terminal (EET), port handles and stores coal and iron ore. The present facility has current holding capacity of 8 million tones. This terminal presents open storage area of 108,500 $\mathrm{m}^{2}$ and is one of the largest bulk cargo terminals in southern Europe.
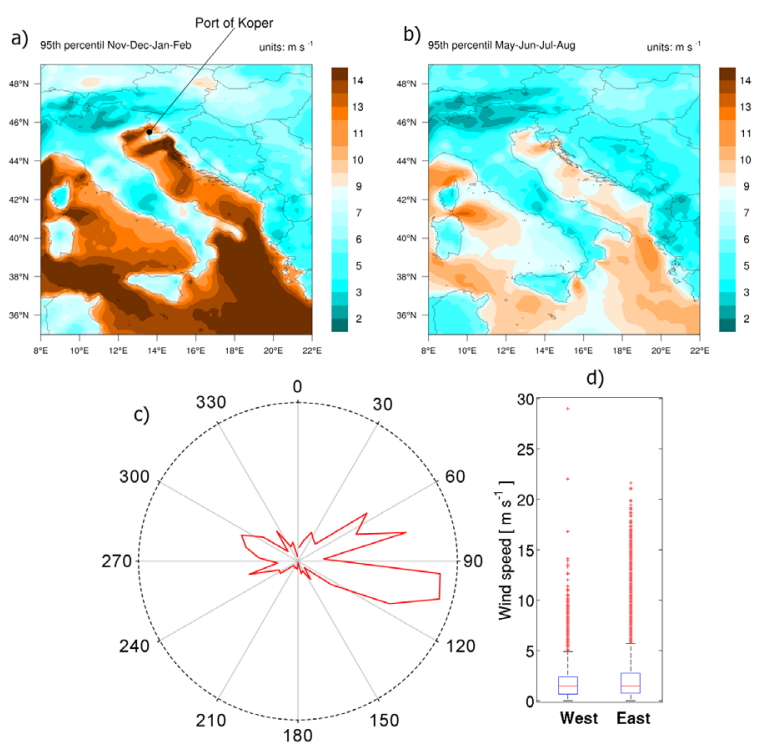

Fig. 1. Regional location and wind conditions at the Port of Koper; 90th percentile of wind speed (ECMWF) above land and sea surface for: a) cold and b) warm period; c) wind rose and d) box plot of measured wind speed for west and east direction

One of the most important factors that influence fugitive emissions is wind speed. Due to the lower sea roughness, wind speed above sea surface is higher than wind speed over land (Fig. 1a). The regional wind speed data was obtained from the European centre for medium-range weather forecasts (ECMWF). Following that, stockpiles located near seashore are usually exposed to higher winds, which lead to higher fugitive dust emissions. Statistical analysis of local wind speed recorded data (at $50 \mathrm{~m}$ above terrain) for the period between august 2012 and august 2013 at the Port of Koper are shown in Fig. 1b. The box plot (Fig. 1d) shows that gusts above $10 \mathrm{~m} / \mathrm{s}$ are more frequent from east direction. 
Nevertheless, maximum gust of $29 \mathrm{~m} / \mathrm{s}$ was recorded from west direction. Furthermore, analysis of maximum wind speeds reveals that the highest speeds were observed from $75^{\circ}$ and $250^{\circ}$ direction. In summary, it is evident that winds from east and occasionally west reach very high speeds and are capable of causing significant dust emissions from the EET stockpile.

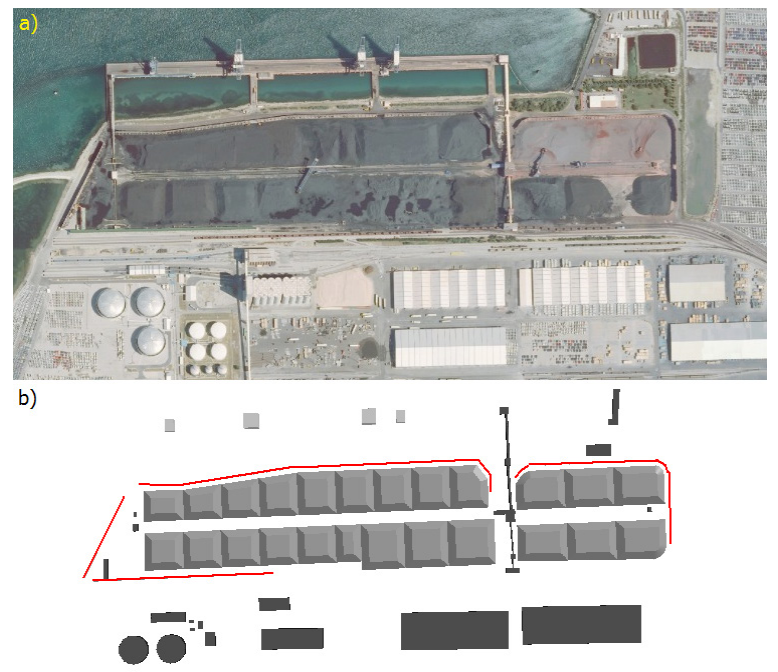

Fig. 2. a) Satellite image of the coal and iron ore stockpile with surroundings; $b$ ) top view of the geometrical model

\subsection{Numerical Method and Model}

Before performing the actual simulations of airflow over the coal and iron ore stockpile, a geometrical model of the site and boundary conditions had to be defined. The geometric 3D model was built on the basis of a satellite image (Fig. 2a) available from Geopedia [12]. It presents an area of $1380 \mathrm{~m}$ length in east-west direction and $730 \mathrm{~m}$ length in north-south direction (Fig. 2b). Vertically, the model was limited to the height of $200 \mathrm{~m}$ above terrain or sea. Minimum extent of the storage site surroundings, included in the model was determined on the basis of guidelines from relevant literature [13]. All significant wind directions and influences of surrounding structures were also taken in consideration and the model was further extended in some directions (i.e. south). Heights of included buildings and structures are presented in Table 1. Port authorities provided all necessary information about stockpiles, adjacent buildings and cranes. Buildings that have no influence on conditions at the stockpile at major wind directions were not included in the model. Basic distribution of piles in the model was made on the basis of the satellite picture and information provided by port authorities.
The height of all piles was $10 \mathrm{~m}$ and base dimension was between $65 \mathrm{~m}$ and $80 \mathrm{~m}$.

Table 1. Buildings and structures in the 3D model

\begin{tabular}{lll}
\hline & & Dimensions $(X \times Y \times Z)[\mathrm{m}]$ \\
\hline & Crane 1 & $25 \times 15 \times 25$ \\
\cline { 2 - 3 } Crane 2 & $25 \times 25 \times 30$ \\
\cline { 2 - 3 } North side objects & Crane 3 & $25 \times 25 \times 30$ \\
\cline { 2 - 3 } & Crane 4 & $20 \times 15 \times 20$ \\
\cline { 2 - 3 } & Building 1 & $16.6 \times 62.1 \times 5.5$ \\
\cline { 2 - 3 } & Building 2 & $42.9 \times 20.7 \times 6$ \\
\hline \multirow{3}{*}{ South side objects } & Building 1 & $53 \times 22 \times 10$ \\
\cline { 2 - 3 } & Building 2 & $105 \times 35 \times 32$ \\
\cline { 2 - 3 } & Building 3 & $182.5 \times 65.4 \times 7$ \\
\cline { 2 - 2 } & Building 4 & $205 \times 65.5 \times 7$ \\
\hline Stockpiles & \multicolumn{1}{c}{65 to $75 \times 65$ to 80 $\times 10$} \\
\hline Reservoir, diameter $=$ & $50 \mathrm{~m}$, height $=15 \mathrm{~m}$ \\
North-south coal conveyor, height $=7 \mathrm{~m} \mathrm{to} \mathrm{10} \mathrm{m}$ \\
\hline
\end{tabular}

Discretization of the geometric model into finite volumes (grid generation) was done with the Ansys ICEM CFD 14.5 software. Grid density was chosen on a basis of grid independence study, which was performed on the single pile case (see section 2.4). At the same time, available computer resources also had to be considered. The final hybrid grid consisted of 14.5 million hexahedral, tetrahedral and prismatic elements. Prismatic elements were used on walls to enable better resolution of the boundary layer. Near wall grid density was designed for the use of wall functions, which provide sufficient accuracy for flows around buildings.

Ansys Fluent 14.5 software was used for the CFD calculations. A Reynolds averaged NavierStokes (RANS) method, which is an industry-standard approach for simulation of atmospheric flows around buildings, was employed. Turbulence was modeled by the $k-\varepsilon$ model [14], which is a proven and robust model, often employed in similar problems. Constants of the model were adjusted to the recommended values for simulation of atmospheric flows according to [15]. Standard wall functions with Fluent's default rough wall formulation [16] were employed. Since Fluent Release 14.0, the default rough wall formulation shifts wall location according to the local roughness height. This eliminates the well known problems associated with mesh resolution at walls with large roughness heights [17], caused by the requirement to keep the first node at the wall outside the specified roughness height.

Air was used as a working fluid assuming incompressibility (i.e. constant density). Steady state conditions were simulated. Second order discretization 
schemes were used for all equations. Calculation reached convergence when the maximum scaled residuals for continuity and momentum equations dropped below $5 \times 10^{-4}$ and for turbulence equations at least below $10^{-3}$.

\subsection{Boundary Conditions}

The model boundary conditions were set to represent the actual conditions at the site. The inlet and outlet boundary surfaces were set in pairs depending on the simulated wind direction. For example, in case of the north-eastern wind directions the inlets were defined on the northern and eastern model boundaries while the outlets were set on the southern and western boundaries. Inlets were defined as velocity $(U)$ inlets with velocity and turbulence quantities $(k, \varepsilon)$ as functions of the vertical coordinate. Standard logarithmic profiles for atmospheric boundary layers were used ([15] and [18]). For illustration, turbulence intensity values, calculated from the inlet profiles as $T u=\sqrt{(2 k / 3)} U$, reach $33.5 \%, 17.2 \%$ and $12.2 \%$ at $1 \mathrm{~m}, 10 \mathrm{~m}$ and $50 \mathrm{~m}$ height, respectively. Terrain roughness length of $0.1 \mathrm{~m}$ was assumed for the profiles, meaning that the average roughness elements are $1 \mathrm{~m}$ high. Outlet boundaries were set as pressure outlets with average relative pressure of $0 \mathrm{~Pa}$.

Walls of buildings and other structures, including the fence, were defined as hydraulically smooth walls with zero slip. Walls representing piles and terrain inside the stockpile fence were set as rough walls with equivalent sand grain roughness of $0.045 \mathrm{~m}$. Terrain outside the fence (both land and sea) was treated as rough wall with equivalent sand grain roughness of 1 $\mathrm{m}$, which takes into account the presence of different objects such as cars, trucks, trains, piers, sea waves etc.). Wall at the top of the model was set as a wall with zero shear stress.

Porous walls were used to represent certain structures, for example cranes located north of the stockpile that were simplified to a cuboid shape. Porous walls were also used to simulate perforated walls and barriers that were included in some of the calculated cases. The porous jump boundary condition type, which can be seen as a model for a thin membrane that has known velocity (pressuredrop) characteristics, was employed for all cases of porous walls. Only inertial resistance (quadratic function of velocity) was prescribed. For cranes and for porous fences the pressure drop at the wall equaled 0.2 times and 4 times the dynamic head of free flow, respectively.

\subsection{Computed Cases}

The prevalent wind directions and intensities were determined on the basis of continuous wind measurements at the site. The measured values provided the complete wind velocity vector at the height of $50 \mathrm{~m}$. Only horizontal velocity component was taken into account since the vertical velocity was significantly smaller. For simulations, cases were defined at precise directions: $75^{\circ}$ and $250^{\circ}$ and two wind velocity magnitudes were considered for the simulations: $18 \mathrm{~m} / \mathrm{s}$ and $22 \mathrm{~m} / \mathrm{s}$.

Taking into account the logarithmic velocity profile, speeds at $50 \mathrm{~m}$ height, $18 \mathrm{~m} / \mathrm{s}$ and $22 \mathrm{~m} / \mathrm{s}$, correspond to $14.85 \mathrm{~m} / \mathrm{s}$ and $18.15 \mathrm{~m} / \mathrm{s}$ at the height of $10 \mathrm{~m}$, respectively. Wind speed values at the height of $10 \mathrm{~m}$ were later used to calculate normalized wind speed and emission factors according to EPA methodology.

In addition to the simulation of base condition representing currently existing structures and fully occupied storage area, additional cases were computed. All the modifications to the base conditions were done with the aim of reducing exposure of piles to high wind velocities. The cases were designated with letters: (A) basic - current condition; (B) existing fence changed into a porous fence; (D) basic condition with piles on the south-west extended closer to the fence; $(\mathrm{H})$ insertion of porous barriers between piles with heights of 11 meters.

Before performing simulations for different cases with the realistic site model, a model with a single pile was prepared to test grid independence and to determine the influence of incoming wind magnitude on normalized velocity distributions. The single pile model covered the same area and height as the realistic site model, but had all the structures and buildings removed. It included only a single pile in the middle of flat terrain. The pile was shaped as a cone with flat top, where bottom radius was $25 \mathrm{~m}$, height was $10 \mathrm{~m}$ and side slope was $37^{\circ}$.

\section{RESULTS AND DISCUSSION}

Fugitive emissions are directly related to the wind speed and predicting wind flow conditions at stockpile surfaces plays an important role for assessment of the erosion potential. CFD results will be therefore presented in form of figures which show a top view of the different degrees of wind exposure over the piles. The piles were divided into subareas of constant $u_{\mathrm{s}} / u_{\mathrm{r}}$, where $u_{\mathrm{s}}$ is wind speed measured $25 \mathrm{~cm}$ from the pile surface and $u_{\mathrm{r}}$ is wind speed reference measured at the 
height of $10 \mathrm{~m}$ above terrain. Furthermore, the emission factors were calculated according to the EPA method [19] where threshold velocity for coal $u_{t}^{*}=1 \mathrm{~m} / \mathrm{s}$ [20] was used. EPA defines emission factors as statistical averages of the rate at which a pollutant is released to the atmosphere as a result of some activity, divided by the level of that activity. Formulae for their calculation are mostly based on regression analysis of relevant measured data. The emission factor for wind-generated particulate emissions from granular materials subject to disturbance is expressed in units of grams per year as follows:

$$
k \sum_{i=1}^{N} P_{i} S_{i} .
$$

In Eq. (1), $k$ is a particle size multiplier, $N$ the number of disturbances per year, $P_{i}$ the erosion potential corresponding to the observed fastest mile of wind for the $i^{\text {th }}$ period between disturbances and $S_{i}$ the pile surface area. Particle size multiplier $(k)$ was set to 0.5 , which corresponds to emissions of $\mathrm{PM}_{10}$ particles [19].

The erosion potential function for a dry, exposed pile surface is defined by Eq. (2):

$$
P=58\left(u^{*}-u_{t}^{*}\right)^{2}+25\left(u^{*}-u_{t}^{*}\right),
$$

where $u_{t}^{*}$ is threshold velocity and $u^{*}$ is given by Eq. (3).

$$
u^{*}=0.1 u_{10}^{+}\left(u_{s} / u_{r}\right)
$$

where $u_{10}^{+}$is the fastest mile of wind at $10 \mathrm{~m}$ height. When friction velocity $u^{*}$ is greater than the threshold friction velocity $u_{t}^{*}$, the erosion potential is positive. Because of the non-linear form of the erosion potential function, each erosion event must be treated separately. Sub-areas of constant $u^{*}$ or $u_{\mathrm{s}} / u_{\mathrm{r}}$ intervals were therefore considered as separate sources and it was assumed that there was only one disturbance per year.

The EPA method by itself is only used to quantify sources of particulate emissions and does not model subsequent transport and dispersion of airborne particles. Its prediction of yearly particulate emissions due to wind erosion was considered sufficient for the purpose of this study. In case spatial distribution of particle concentration would be required, then an additional dispersion model would need to be included in the simulations [21].

\subsection{Single Pile Case}

Grid refinement on the single pile case included three grids of variable element size near the pile (4 $\mathrm{m}, 2 \mathrm{~m}$ and $1 \mathrm{~m}$ maximum edge length). While finer grids showed slightly more detail in the velocity distributions, they did not show any major changes in their patterns. It was decided that the maximum edge length of $2 \mathrm{~m}$ at the pile surface, $4 \mathrm{~m}$ on terrain away from the pile and $7 \mathrm{~m}$ on distant surfaces provided sufficient resolution for final calculations. The same grid density was applied also for the realistic stockpile model, but with additional refinements near structures (i.e. $1 \mathrm{~m}$ max. element edge on the fence).
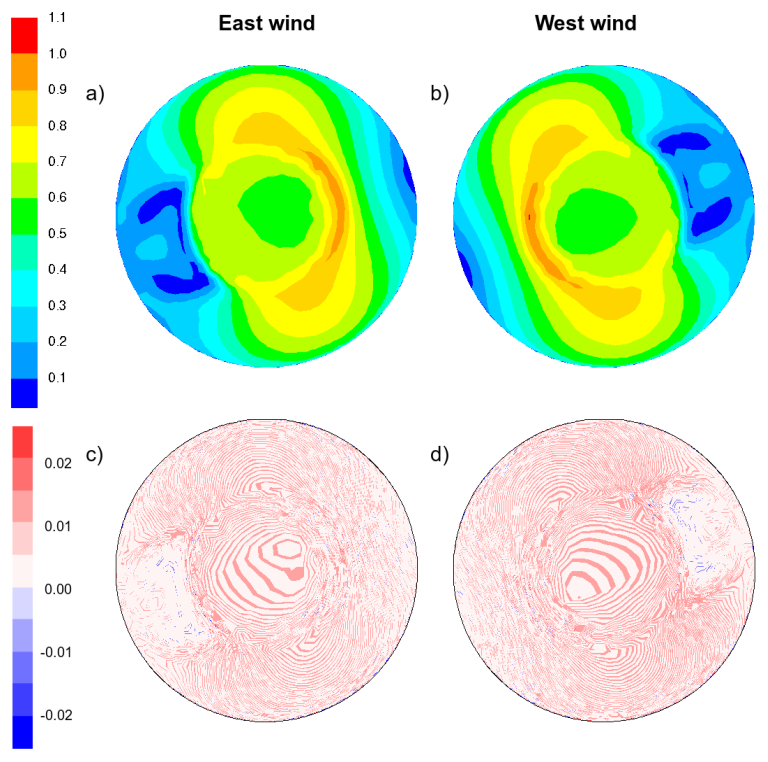

Fig. 3. a) and b) Top view of us/ur contours at $25 \mathrm{~cm}$ from the flattopped pile surface for wind magnitude $18 \mathrm{~m} / \mathrm{s}$;

c) and d) top view of difference between us/ur contours at magnitudes of $U=22 \mathrm{~m} / \mathrm{s}$ and $U=18 \mathrm{~m} / \mathrm{s}$

Influence of the incoming wind magnitude on normalized velocity distribution was studied by performing calculations at two magnitudes, $U=18$ $\mathrm{m} / \mathrm{s}$ and $U=22 \mathrm{~m} / \mathrm{s}$. Difference in results for the both magnitudes is shown by subtracting the normalized velocities $u_{\mathrm{s}} / u_{\mathrm{r}}$ for the $U=18 \mathrm{~m} / \mathrm{s}$ case from the $U=22 \mathrm{~m} / \mathrm{s}$ case and presenting this difference in form of contour plot. Results shown in Fig. 3 show only minimal differences (up to \pm 0.02 ) for the both wind directions $\left(75^{\circ}\right.$ and $250^{\circ}$ ) and therefore confirm independence of normalized velocity from the incoming wind magnitude and direction. These results are consistent with study of Badr and Harion [4] in which the normalized wind speed over a simple geometry was shown to be independent of the incoming wind velocity magnitude. However, the realistic configuration included multiple piles with adjacent structures, therefore the normalized wind speed distributions in the realistic model are expected 
to show some dependence on the incoming wind conditions.

\subsection{Case A - Current State}

Fig. 4 presents current state conditions (case A) for two wind speeds for both west and east direction. It is evident that intermediate and high normalized velocities occur on top of the piles for the both wind directions. Generally, highest wind exposure is seen on pile edges. Wind exposure in case of west wind is higher than in case of the equally strong east wind, which indicates that existing wind protection is less effective in case of the west wind. In fact, the solid fence in the western part of the site is placed further away from the piles and at an angle, which provides favorable conditions for air currents to penetrate lower. The west wind also has fewer obstructions on its way over the central east-west oriented road, which is used by the coal stacking and reclaiming machinery. Therefore, higher wind exposure on the

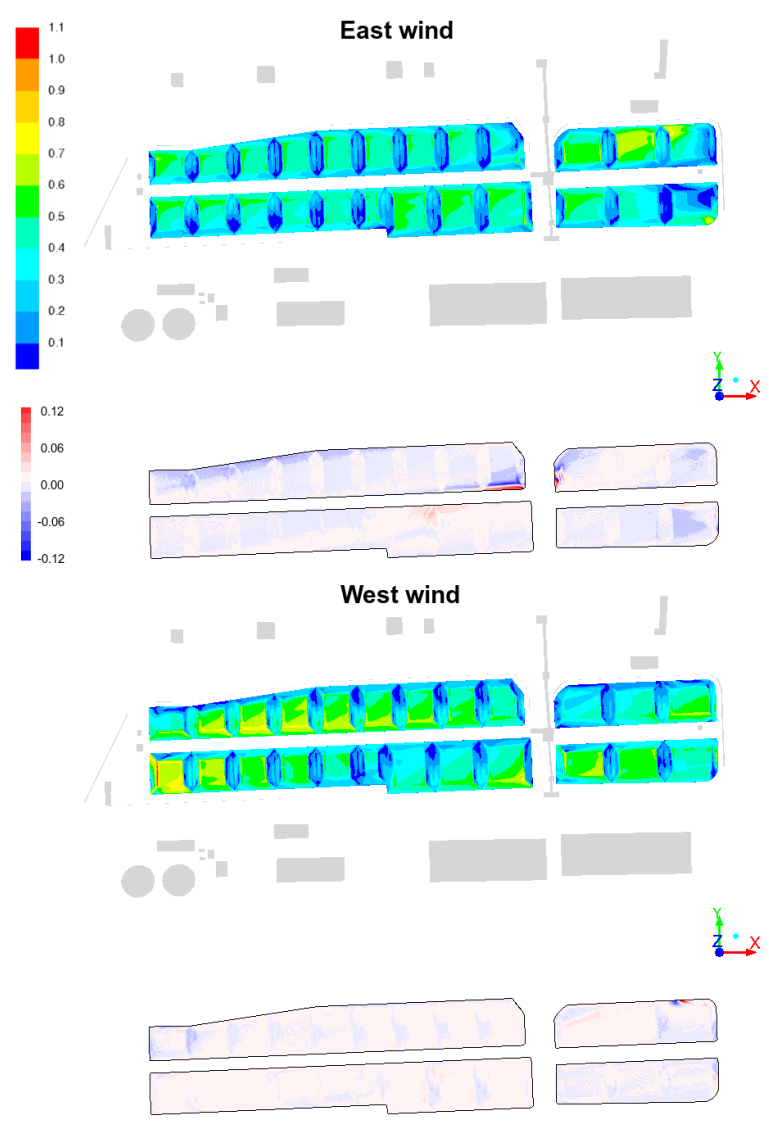

Fig. 4. Case A for east and west wind; top view of us/ur contours in rainbow color map and difference between us/ur contours at magnitudes of $U=22 \mathrm{~m} / \mathrm{s}$ and $U=18 \mathrm{~m} / \mathrm{s}$ in red-blue color map piles downwind from the central road can be seen for the case of west wind.

Both wind directions were calculated at two incoming wind magnitudes, $U=18 \mathrm{~m} / \mathrm{s}$ and $U=22$ $\mathrm{m} / \mathrm{s}$. From Fig. 4 it can be seen that differences in results for the both magnitudes are very small for both wind directions. On average, a slight reduction in wind exposure is indicated for the higher wind magnitude, especially in case of east wind. Isolated spots with local differences of up to \pm 0.12 indicate shifts in flow structures (vortices), caused by the objects located upwind.

\subsection{Case B - Porous Fence}

Proper installation of porous fences and windbreak barriers can reduce dust emissions and protect coal stockpiles against high wind velocities [22]. The installation of porous fences that yields optimal protection is a challenging task and has been studied by several researchers. Reported wind tunnel investigations include measurements of surface pressure fluctuations on a prism behind a porous fence [23] and [24] or measurements of sand particle movement from a pile located behind a porous fence [25]. Field measurements on actual port stockpiles combined with CFD simulations are reported in [7] and [26], while a recent numerical study on a single pile is reported in [27]. These studies provide valuable knowledge for selecting optimal fence parameters such as location, height and porosity, but with regard to a single pile or to regular arrays of piles.

Replacement of the solid fence with a porous one was the first simulated measure for wind exposure reduction (Figs. 5 and 6). In case of solid barriers, the airflow is initially pushed over the barrier but then quickly lowers and continues without significant reduction in velocities. A vortex is formed leeward from the solid barrier, which can additionally deteriorate local conditions. On the other hand, porous barriers allow passing of fluid at a reduced velocity. This means that a region of reduced wind speed without any vortices is expected to form and stretch further downstream compared to the solid barrier case.

Fig. 5 shows streamlines for west wind at $18 \mathrm{~m} / \mathrm{s}$ for solid fence (case A) and porous fence (case B). The eastern part of the stockpile is shown and wind blows towards the camera position. Streamlines originate from a surface of $2 \mathrm{~m}$ height, located just above the fence.

It is clearly seen that the existing solid fence causes many vortices that are pushed towards the stockpile edges, leaving the central part of piles 
exposed. The porous fence on the other side eliminates any large-scale vortices and allows a uniform flow over the entire stockpile.

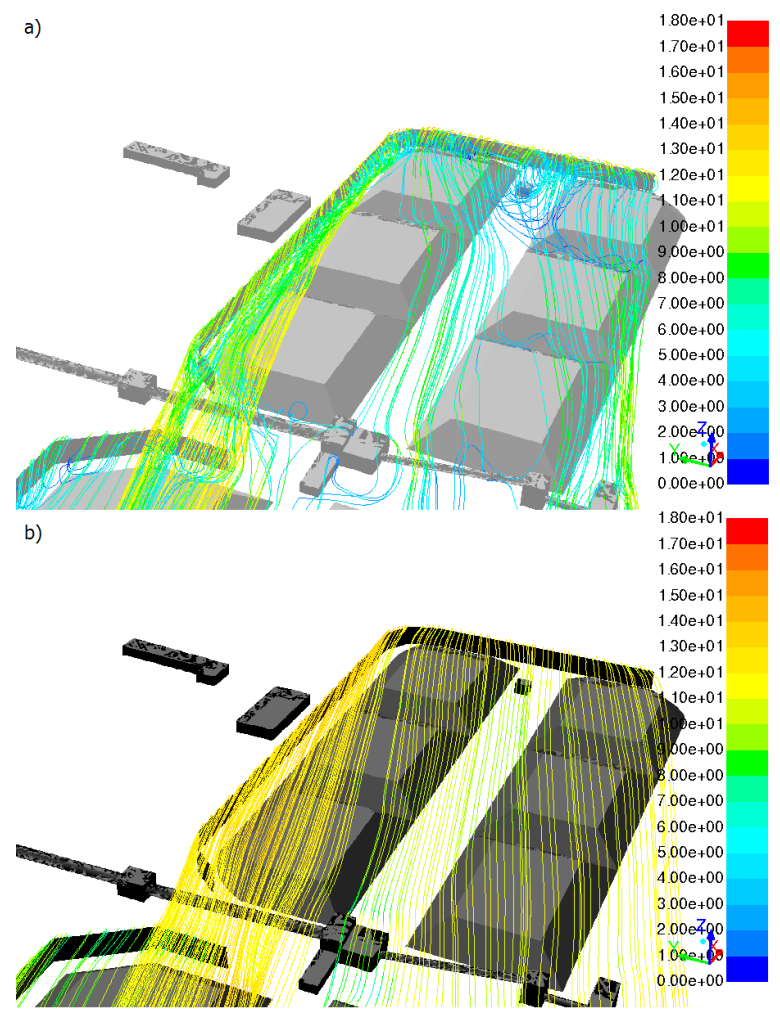

Fig. 5. Streamlines for east wind at $18 \mathrm{~m} / \mathrm{s}$; a) solid-fence-case $A$; b) porous-fence-case $B$

Fig. 6 shows normalized velocity distributions above piles for both east and west wind with the porous fence. Reduced wind exposure compared to the solid fence (Fig. 4) can be seen on some of the piles, while on the other piles, wind exposure seems to be unaffected or even increased. Reasons for limited porous fence effectiveness can be attributed to the large size of the terminal, which stretches in the direction of dominant winds, and to the sharp angle of incoming winds relative to the fence. Nevertheless, the largest wind speed reduction occurs at locations with the largest velocity magnitude while an increase mostly occurs at spots with relatively low wind velocities, meaning that velocity distribution becomes more uniform and has fewer extremes.

Since the wind erosion is only problematic at a relatively large wind velocity over piles, there is clearly an advantage of a porous fence (case B) in comparison with a solid fence (case A). This is confirmed by a reduction in total dust emissions which are lower in case B (consider the section 2.6 for details). Differences between the $U=18 \mathrm{~m} / \mathrm{s}$ and the
$U=22 \mathrm{~m} / \mathrm{s}$ cases are low and on average show slightly smaller normalized velocities for the case of $U=22$ $\mathrm{m} / \mathrm{s}$. This can be attributed to the non-linear resistance characteristic of the porous fence, which was set as a quadratic function of the upstream velocity.
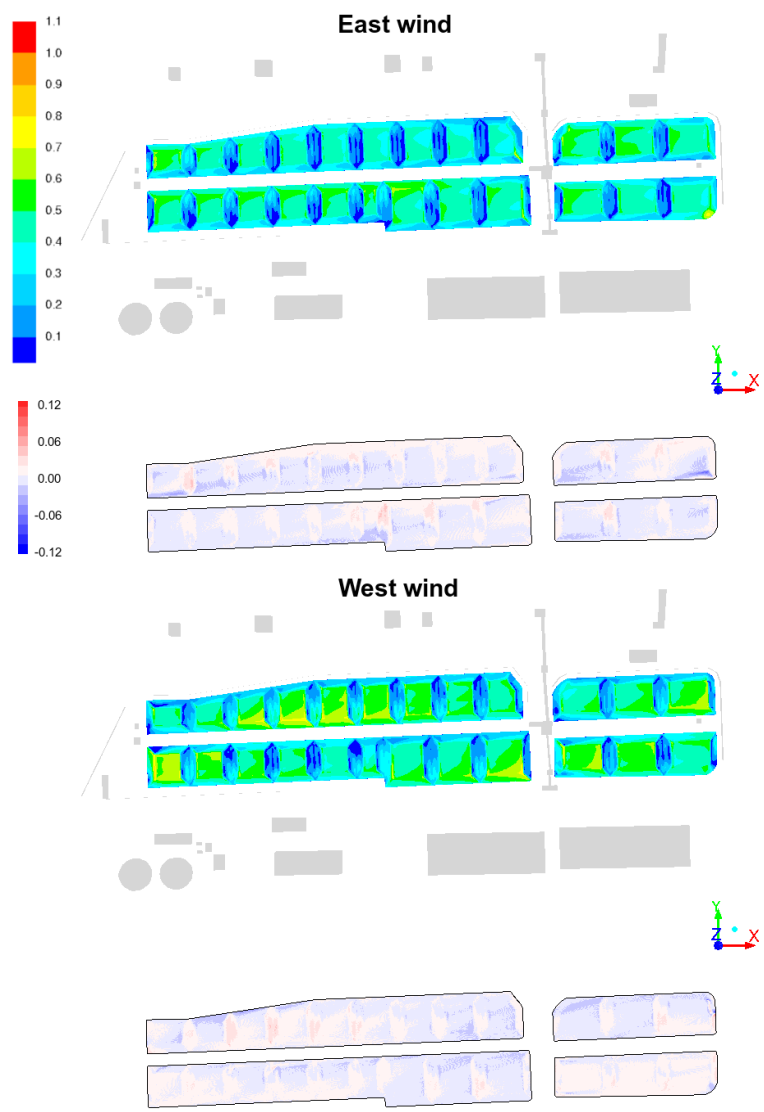

Fig. 6. Case B for east and west wind; top view of us/ur contours in rainbow color map and difference between us/ur contours at magnitudes of $U=22 \mathrm{~m} / \mathrm{s}$ and $U=18 \mathrm{~m} / \mathrm{s}$ in red-blue color map

\subsection{Case D - Distribution of Stockpiles}

Another possible measure for wind exposure reduction at the site would be to optimize distribution and size of piles. Numerous combinations of pile locations and sizes are possible in theory but in practice they are limited by the technical possibilities of the stacking and reclaiming machinery. Furthermore, technical and logistical requirements dictate filling and emptying of the stockpile and the length of individual piles. Therefore it is difficult to perform such optimization in reality, even if simulations indicated significant benefits.

Fig. 7 shows basic condition, very similar to case A, but with piles on the south-west extended closer to the fence. No significant differences in normalized 
velocities can be seen relative to case A. However, differences between the $U=18 \mathrm{~m} / \mathrm{s}$ and the $U=22$ $\mathrm{m} / \mathrm{s}$ cases are more evident in case D than case A. Especially in case of west wind, the effect of southern fence seems to not scale linearly with the incoming wind magnitude - lower normalized velocities are computed downwind from the fence at the higher incoming wind velocity magnitude.
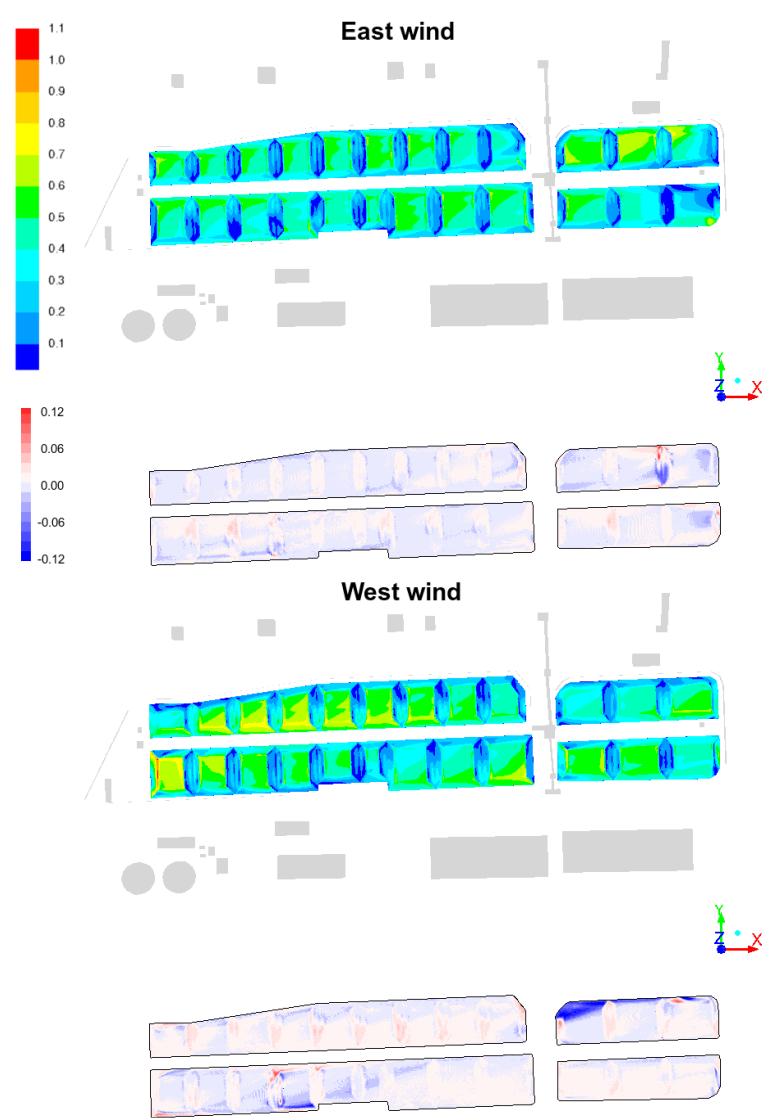

Fig. 7. Case $D$ for east and west wind; top view of us/ur contours in rainbow color map and difference between us/ur contours at magnitudes of $U=22 \mathrm{~m} / \mathrm{s}$ and $U=18 \mathrm{~m} / \mathrm{s}$ in red-blue color map

\subsection{Case H - Transverse Porous Barriers}

As said, effectiveness of both solid and porous fences in reducing wind velocities above piles is greatly limited due the stretched shape and orientation of the cargo terminal and surrounding fences relative to the incoming wind direction. Major portions of the fence are hit by wind at sharp angles and the resulting area of reduced wind velocity downstream the fence is too short to reach piles further away. Therefore, a different approach for wind damping was proposed. Porous barriers between piles that were oriented transverse to the main winds were included into the numerical model (Fig. 8). Three porous barriers were placed at the south-western part of the stockpile to test the method mostly for west wind and another barrier was placed on the eastern edge of the south-western row of piles. All the barriers were $11 \mathrm{~m}$ high.

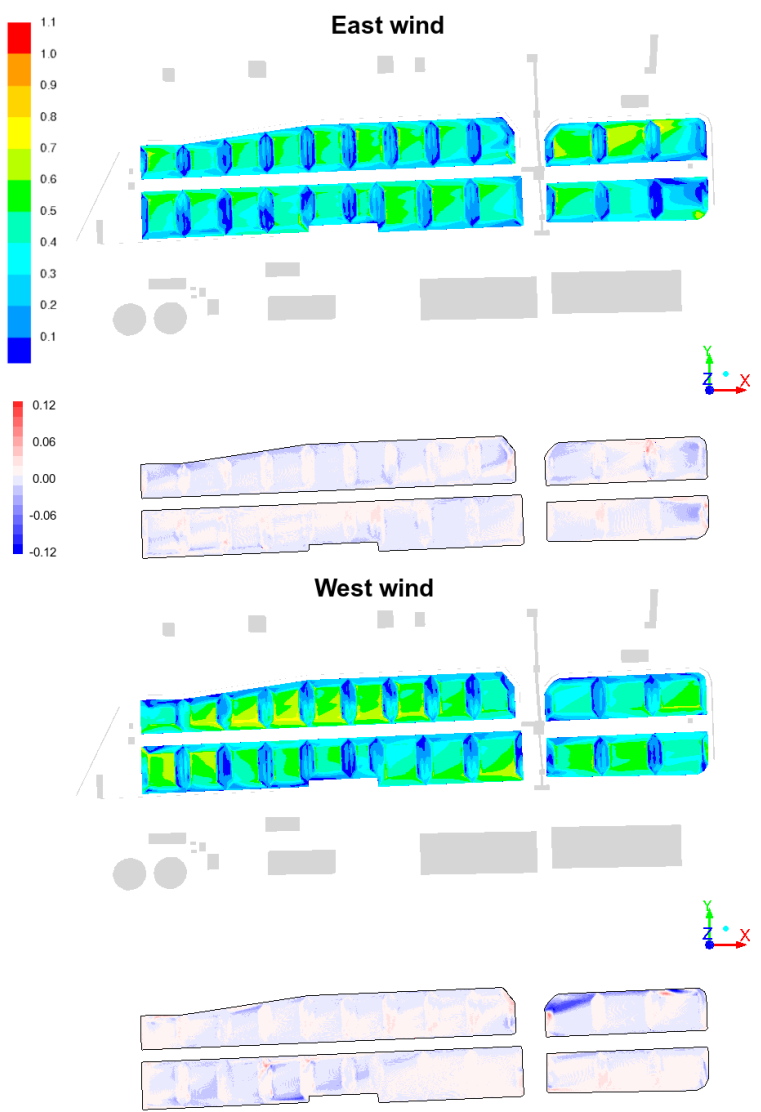

Fig. 8. Case $H$ for east and west wind; top view of us/ur contours in rainbow color map and difference between us/ur contours at magnitudes of $U=22 \mathrm{~m} / \mathrm{s}$ and $U=18 \mathrm{~m} / \mathrm{s}$ in red-blue color map

Positive effects of the barriers are evident mostly in case of west wind. Wind exposure is significantly reduced for the first pile and partially also for the second pile downwind from the barrier. On average, differences between the $U=18 \mathrm{~m} / \mathrm{s}$ and the $U=22$ $\mathrm{m} / \mathrm{s}$ cases show smaller normalized velocities in case of $U=22 \mathrm{~m} / \mathrm{s}$. As in the case of the porous fence (case B), this can be partly explained by the resistance characteristic of the barriers, which was set as a quadratic function of the upstream velocity.

\subsection{Comparison of B-A and H-D Cases}

Effects of modified/additional wind protection measures compared to the basic (current state) conditions are presented in Fig. 9. Case B (porous 
fence) is compared to case A by calculating absolute difference between the normalized velocities at $U=$ $18 \mathrm{~m} / \mathrm{s}$. In the same way, case $\mathrm{H}$ (four porous barriers) is compared to case D. Calculated differences are presented in form of contour plots, where color map is set to represent values between -0.2 and +0.2 . Local differences can slightly exceed these values, but the color map was intentionally set to cap the extreme values in order to better present the bulk differences.

B-A
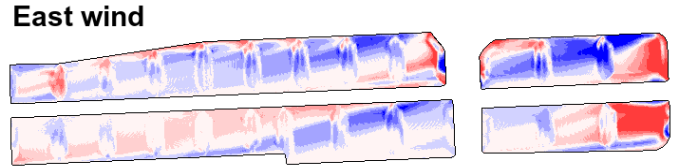

H-D

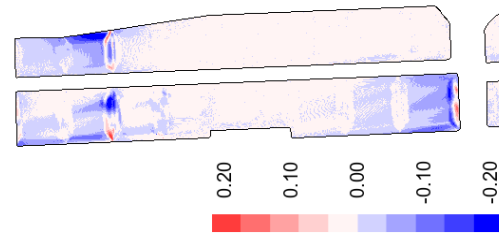

West wind

B-A
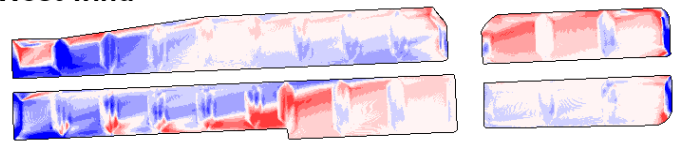

H-D
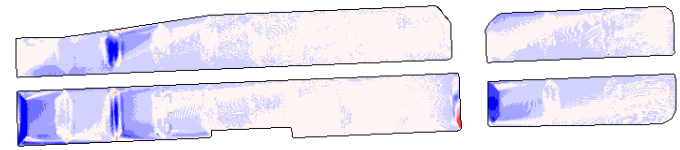

Fig. 9. Top view of difference between us/ur contours for B-A, and $H-D$ case $(U=18 \mathrm{~m} / \mathrm{s})$

Comparison of case B to case A shows that replacement of the existing solid fence by a porous fence would produce extensive regions of both reduced and increased wind exposure for the both wind directions. It is again evident that the large size of the dry bulk cargo terminal and its orientation relative to the direction of dominant winds present a challenging configuration for wind protection by porous fence that simply runs around the terminal perimeter. Judging from the normalized velocity differences, replacement of solid fence with a porous one seems to yield no overall benefits in wind protection, however, when taking into account emissions (see Fig. 10), benefits become evident. Results shown in Fig. 10 reveal that dust emission rates are lower for case B (porous fence); they are reduced by $50 \%$ for both east and west wind. When comparing west and east wind emission rates it can be seen that the west wind emission rate is almost 10-times higher than the east wind emission rate (Fig. 10). The reason for much higher west wind emission rate is that fence in the western part of the site is less efficient in wind protection. Its location further away from the piles and its orientation relative to direction of incoming west wind provide conditions for air currents to penetrate lower and attain higher wind velocities above the piles.

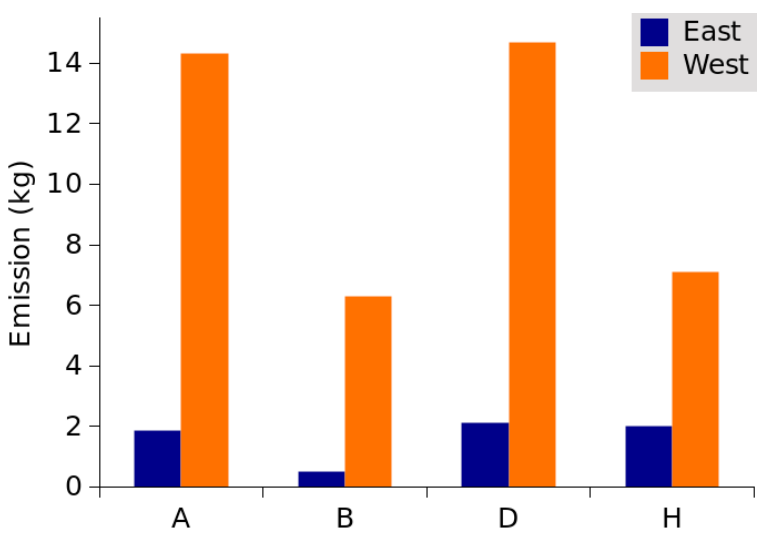

Fig. 10. Total dust emissions under west and east wind flow for $A, B, D$ and $H$ case

On the other hand, placement of porous barriers that are oriented transverse to the main wind directions (case $\mathrm{H}$ ) clearly shows a highly positive effect. In this case, normalized velocities are significantly reduced for the first pile and partially also for the second pile downwind from the barrier. In case of west wind positive effects of barriers can be seen also on other piles in the wider stockpile area. Lower emission rates in case $\mathrm{H}$ are observed only for west wind while east wind emission rate is unchanged (Fig. 10). The reason for unchanged emission rate in case of east wind is that emissions in this case mostly occur on the eastern piles, so barriers placed further downwind are not effective in reducing critical wind velocities. In fact, most barriers in the model were intentionally placed at the south-western part of the stockpile to test their effectiveness mostly for west wind. In this respect, much lower emission reduction in case of east wind is not surprising. Further emission reductions for both wind directions could most probably be achieved by performing optimization of barrier locations, size and porosity parameters.

\section{CONCLUSIONS}

Simulations of wind conditions at the coal and iron ore stockpile at the Port of Koper were performed by employing CFD tools to assess the problem of dusting. Experimental validation by wind tunnel measurements or field experiments was not performed due to limited 
time and resources available, but should preferably be executed in the future. Wind exposure of piles was analyzed for different wind conditions and by application of various physical measures for reduction of wind velocity. Results of simulations show that the existing solid fence provides a very limited protection from high winds due to the size and stretched shape of the stockpile area and its orientation relative to the main wind directions. Modifications to the fence by replacing it with porous structures were simulated and showed that their efficiency is limited for the same reasons as in the case of solid fence, although the total emission rate could be significantly reduced.

An efficient measure for reduction of wind velocity over the piles was found to be placement of porous barriers between the piles, oriented transverse to the main wind directions. However, such barriers on the real stockpile could impose significant limitations for the material stacking and reclaiming machinery. Watering and spraying with crust-forming liquids still remain a necessary step for prevention of wind erosion and fugitive emissions. Nevertheless, maps of local wind velocities that were created by the simulations enable identification of critical spots for occurrence of dusting and in this way help in optimization of spraying and reduction of associated costs.

The study showed that wind reduction by physical measures such as barriers is a very challenging task when dealing with large stockpiles and strong winds. Numerous dust emission research was done for single piles or regular arrays of piles, however, realistic sites are often hardly compared to such cases. Presence of adjacent fences, buildings, structures and irregular pile layouts have shown to have an important influence on wind conditions and should therefore always be taken into account when doing wind exposure analysis for real sites.

\section{ACKNOWLEDGEMENTS}

We would like to thank the port authorities for providing data for this research. This research was supported in part by European Union (European development fund, Interreg SLO-ITA, 2007-2013, project SAFEPORT - The port and industrial and environmental risk management) and in part by Slovenian Research Agency under research grants L75554 and P1-0294.

\section{REFERENCES}

[1] Bagnold, R.A. (1941). The Physics of Blown Sand and Desert Dunes. Methuen and Co., London.
[2] World health organization (2009). Global Health Risk: Mortality and Burden of Diseases Attributable to Selected Major Risks. p. 23-53.

[3] Badr, T., Harion, J.L. (2005). Numerical modelling of flow over stockpiles: Implications on dust emissions. Atmospheric Environment, vol. 39, no. 30, p. 5576-5584, D0l:10.1016/j. atmosenv.2005.05.053.

[4] Badr, T., Harion, J.L. (2007). Effect of aggregate storage piles configuration on dust emissions. Atmospheric Environment, vol. 41, no. 2, p. 360-368, Dol:10.1016/j. atmosenv.2006.07.038.

[5] Toraño, J.A., Rodriguez, R., Diego, l., Rivas, J.M., Pelegry, A. (2007). Influence of pile shape on wind erosion CFD emission simulation. Applied Mathematical Modelling, vol. 31, no. 11, p. 2487-2502, D0I:10.1016/j.apm.2006.10.012.

[6] Turpin, C., Harion, J.L. (2009). Numerical modeling of flow structures over various flat-topped stockpiles height: Implications on dust emissions. Atmospheric Environment, vol. 43, no. 35, p. 5579-5587, D0l:10.1016/j. atmosenv.2009.07.047.

[7] Cong, X.C., Cao, S.Q., Chen, Z.L., Peng, S.T., Yang, S.L. (2011). Impact of the installation scenario of porous fences on windblown particle emission in open coal yards. Atmospheric Environment, vol. 45, no. 30, p. 5247-5253, D0l:10.1016/j. atmosenv.2011.07.005.

[8] Turpin, C., Harion, J.L. (2010). Numerical modelling of flow structures over an industrial site: effect of the surrounding buildings on dust emissions. Global NEST Journal, vol. 12, no. 1, p. 40-45.

[9] Diego, I., Pelegry, A., Torno, S., Toraño, J., Menendez, M. (2009). Simultaneous CFD evaluation of wind flow and dust emission in open storage piles. Applied Mathematical Modelling, vol. 33, no. 7, p. 3197-3207, D0l:10.1016/j. apm.2008.10.037.

[10] Cong, X.C., Yang, S.L., Cao, S.Q., Chen, Z.L., Dai, M.X., Peng, S.T. (2012). Effect of aggregate stockpile configuration and layout on dust emissions in an open yard. Applied Mathematical Modelling, vol. 36, no. 11, p. 5482-5491, D0l:10.1016/j. apm.2012.01.014.

[11] Furieri, B., Santos, J.M., Russeil, S., Harion, J.-L. (2014). Aeolian erosion of storage piles yards: contribution of the surrounding areas. Environmental Fluid Mechanics, vol. 14, no. 1, p. 51-67, D0l:10.1007/s10652-013-9293-4.

[12] Geopedia, from http://www.geopedia.si/\#T105_ F1173:6064_x402189.531_y47286.32_s17_b2, accessed on 2013-09-30.

[13] Tominaga, Y., Mochida, A., Yoshie, R., Kataoka, H., Nozu, T., Yoshikawa, M., Shirasawa, T. (2008). AlJ guidelines for practical applications of CFD to pedestrian wind environment around buildings. Journal of Wind Engineering \& Industrial Aerodynamics, vol. 96, no. 10-11, p. 1749-1761, D0l:10.1016/j.jweia.2008.02.058.

[14] Launder, B.E., Spalding, D.B. (1974). The numerical computation of turbulent flows. Computer Methods in Applied Mechanics and Engineering, vol. 3, no. 2, p. 269-289, DOl:10.1016/0045-7825(74)90029-2.

[15] Mandas, N., Cambuli, F., Crasto, G., Cau, G. (2004). Numerical simulation of the Atmospheric Boundary Layer (ABL) over 
complex terrains. Proceedings of European Wind Energy Conference, London.

[16] ANSYS Inc. (2012). ANSYS Fluent, Release 14.5, User's Guide.

[17] Blocken, B., Stathopoulos, T., Carmeliet, J. (2007). CFD simulation of the atmospheric boundary layer: wall function problems. Atmospheric Environment, vol. 41, no. 2, p. 238252, DOl:10.1016/J.atmosenv.2006.08.019.

[18] Richards, P.J., Hoxey, R.P. (1993). Appropriate boundary conditions for computational wind engineering models

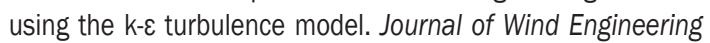
\& Industrial Aerodynamics, vol. 46-47, p. 145-153, DOI:10.1016/0167-6105(93)90124-7.

[19] EPA (2006). Update of Fugitive Dust Emissions Factors In AP-42 Section 13.2.5 - Wind Erosion. Midwest Research Institute, Kansas City.

[20] Topić N., Žitnik M. (2012). Fugitive Dust Emissions from a Coal-, Iron Ore- and Hydrated Alumina Stockpile. Khare, M. (ed.). Air Pollution - Monitoring, Modelling and Health. P. Intech, p. 197222, Dol:10.5772/33741.

[21] Hriberšek M., Samec N., Ravnik J., Zadravec, M. (2011). Numerical Simulations of Wind Induced Particle Contamination in Gypsum Landfill Surroundings. Environmental Modeling \& Assessment, vol. 16, no. 5, p. 479-489, Dol:10.1007/s10666011-9255-5.

[22] Borges, A., Viegas, D. (1988). Shelter effects on a row of coal piles to prevent wind erosion. Journal of Wind Engineering
\& Industrial Aerodynamics, vol. 29, no. 1-3, p. 145-154, DOI:10.1016/0167-6105(88)90153-5.

[23] Lee, S.J., Park, C.W. (1998). Surface-pressure variations on a triangular prism by porous fences in a simulated atmospheric boundary layer. Journal of Wind Engineering \& Industrial Aerodynamics, vol. 73, no. 1, p. 45-58, Dol:10.1016/S01676105(97)00276-6.

[24] Lee, S.J., Park, C.W. (1999). Surface pressure characteristics on a triangular prism located behind a porous fence. Journal of Wind Engineering \& Industrial Aerodynamics, vol. 80, no. 1-2, p. 69-83, D0I:10.1016/S0167-6105(98)00195-0.

[25] Lee, S.J, Park, K.C., Park, C.W. (2002). Wind tunnel observations about the shelter effect of porous fences on the sand particle movements. Atmospheric Environment, vol. 36, no. 9, p. 1453-1463, D0I:10.1016/S1352-2310(01)00578-7.

[26] Cong, X.C, Du, H.B., Peng, S.T., Dai, M.X. (2013). Field measurements of shelter efficacy for installed wind fences in the open coal yard. Journal of Wind Engineering and Industrial Aerodynamics, vol. 117, p. 18-24, D0I:10.1016/j. jweia.2013.04.004.

[27] Song, C.F, Peng, L., Cao, J.J., Mu, L., Bai, H.L., Liu, X.F. (2014). Numerical simulation of airflow structure and dust emissions behind porous fences used to shelter open storage piles. Aerosol and Air Quality Research, vol. 14, no. 6, p. 15841592, D0l:10.4209/aaqr.2013.11.0331. 